\title{
Changes in perceived contrast, reaction time, and pattern-specific evoked potentials due to stimulus duration
}

\author{
ISTVÁN CZIGLER and MIKLÓS TÖLGYESI \\ Institute for Psychology, Budapest, Hungary
}

\begin{abstract}
Using patterned stimulation without luminance change, the authors manipulated the stimulus duration and measured three variables: the magnitude of contrast experience, simple reaction time, and the amplitude of pattern-specific visual evoked potentials. While contrast experience, measured by the scaling method, indicated no saturation below $85 \mathrm{msec}$, the other two variables saturated below $40 \mathrm{msec}$. The lower saturation value of the pattern-specific evoked potential is considered as the limit of the correlation between psychophysical measures and brain electric activity. This suprathreshold divergence can be seen as evidence that processes underlying the pattern-specific visual evoked potential components cannot be considered as mechanisms mediating subjective experience of spatial contrast.
\end{abstract}

Evoked potentials are frequently considered as a useful tool in order to obtain objective correlates of sensory functioning. So, in the visual modality, acuity measures using evoked potential methods even have some practical significance (see, e.g., Harter \& White, 1970; Marg, Freeman, Peltzman, \& Goldstein, 1976; Sokol, 1978). There are also close relationships between some threshold estimates based on visual evoked potentials (VEPs) and the psychophysical thresholds (Campbell \& Kulikowski, 1972; Campbell \& Maffei, 1970), and between the behavior of some evoked potential measures and psychophysical functions above threshold level (Fiorentini \& Maffei, 1973; Vaughan \& Hull, 1965).

Another correlate of perceptual experience is the reaction time (RT). Cattell (1886) observed an inverse relation between the intensity of visual stimuli and RT. The power function relationship between intensity and RT (Piéron's law) is similar to the psychophysical functions appearing under similar circumstances. Evoked potential changes may correlate with these measures. Vaughan, Costa, and Gilden (1966) found a power function relationship between the stimulus intensity, on one hand, and the latency of a VEP component and the reaction time, on the other hand. ${ }^{1}$

Similarities among the changes of the three variables (psychophysical judgment, VEP, and RT) as a function of stimulus intensity seem to be fairly impressive; however, it may be important to investigate more directly the relationship of these variables. On a theoretical level, the break of the correlation would indicate the limits of reductionalist views concerning the generation of subjective experience, while on a level of information processing models, the different kinds of reaction demands imposed by these measures may reveal certain characteristics of the mechanisms involved in visual perception.

In the following experiments, our aim was to estimate the saturation level of three measures, using the appearance of high-contrast patterns as stimulation and manipulating the stimulus duration as an independent variable. VEP to patterned stimulation without luminance change consists of three components: CI, CII, and CIII, with approximately 75 , 100 , and $160 \mathrm{msec}$ latency, respectively. The polarity of these components depends on the stimulated half of the visual field. Using lower half-field stimulation, the $\mathrm{CI}$ and CIII are negative and the CII is positive (Jeffreys \& Axford, 1972a, 1972b). Spekreijse, Van der Tweel, and Zuidema (1973) described a Bloch's law analog of the stimulus duration-spatial contrast relationship, using VEP amplitude (CII) as a dependent variable. They also reported that in increasing the stimulus duration, the saturation level of pattern-specific VEP components depends on spatial contrast (Spekreijse, Van der Tweel, \& Zuidema, 1973, Figure 14). Using high-contrast stimuli, the amplitude of the most prominent pattern-specific VEP component (CII) saturates in the range of 25-30 msec (Jeffreys \& Axford, 1972b, Figure 5). While no a priori prediction can be made concerning the saturation level of the other two variables, some informal observations suggested a much higher saturation level of contrast magnitude estimation.

\section{EXPERIMENT 1}

\section{Stimulus Duration and Contrast Experience}

In this experiment, we used a variation of Stevens' 
scaling method (Stevens, 1971) in order to evaluate the relationship between the stimulus duration and the perceived magnitude of subjective contrast.

\section{Method}

Subjects. The subjects were 16 students and staff members, nine males and seven females, 19-31 years old. They were unaware of the fact that in the experiment, the real independent variable was the stimulus duration.

Apparatus and Procedure. Stimuli were provided by a Scientific Prototype GB tachistoscope. Stimuli were high-contrast transparencies consisting of dark squares disposed in six rows and 10 columns. From the $120-\mathrm{cm}$ viewing distance, each square subtended $19 \mathrm{~min}$ of visual angle. This pattern appeared in the lower half of the visual field and occupied $5 \times 7 \mathrm{deg}$ of visual angle. The luminance of the stimulus and of the interstimulus field was equal, that is, 8,16 , or $32 \mathrm{~cd} / \mathrm{m}^{2}$ in different conditions. A warning click started each experimental trial. The standard 5 -msec stimulus occurred after $1,500 \mathrm{msec}$, followed by the test stimulus. The interval between the two stimuli was $1,000 \mathrm{msec}$. Duration of the test stimulus was $5,15,25,35,45,55,65,75$, or $85 \mathrm{msec}$. Sessions were preceded by a 5 -min adaptation period. At the beginning of the session, the subjects were provided several times with the standard stimulus. They were informed about the stimulus sequence and asked to assign any number they wished to the standard stimulus. They were told that in each trial the same standard would be exposed in order to "refresh the memory trace for the standard contrast." The subjects were asked to fixate on a centrally located fixation cross. The task was to assign a numeric value to the test stimulus, proportional to the subjective contrast experience of the standard. Each test stimulus appeared twice at each luminance value. Trials were arranged in different random orders. The serial positions and the luminance values were counterbalanced among the subjects.

\section{Results and Discussion}

In order to obtain scale values, the two responses for a given stimulus duration were averaged, and the 16 subjects' geometric mean was calculated. Results are shown in Figure 1. As is evident from the figure,

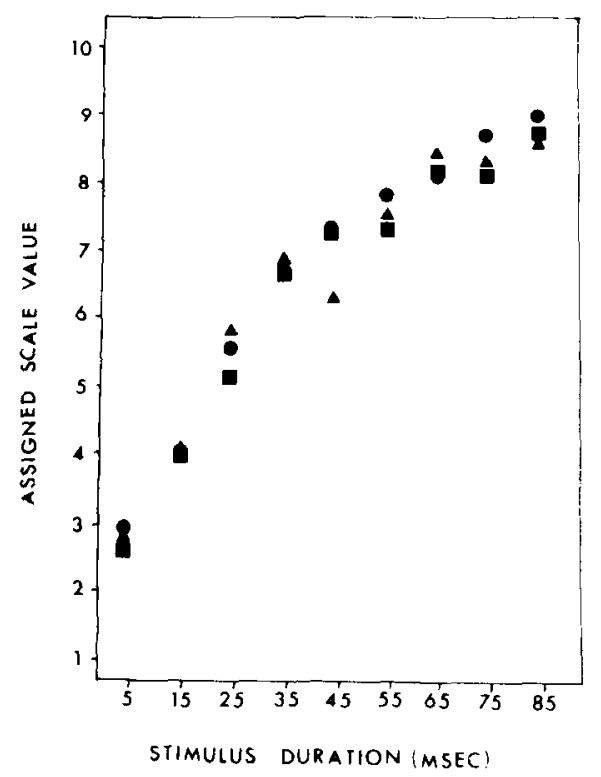

Figure 1. Estimated spatial contrast as a function of stimulus duration (Experiment 1). Geometric means of 16 subjects' scale values: $\bullet=8, \square=16$, and $\Delta=32 \mathrm{~cd} / \mathrm{m}^{2}$ interstimulus field luminance.
Table 1

Parameters of Logarithmic and Power Functions Fitted to the Average Scale Values of Experiment 1

\begin{tabular}{|c|c|c|c|c|}
\hline & \multicolumn{4}{|c|}{ Fitted Functions } \\
\hline & \multicolumn{2}{|c|}{ Logarithmic* } & \multicolumn{2}{|c|}{ Power** } \\
\hline & $y_{0}=0$ & $y_{0}=5$ & $y_{0}=0$ & $y_{0}=5$ \\
\hline & \multicolumn{4}{|c|}{$\mathrm{ISF}=8 \mathrm{~cd} / \mathrm{m}^{2}$} \\
\hline b & -1.09 & -1.23 & 1.58 & 1.86 \\
\hline $\mathrm{m}$ & 2.23 & 2.43 & .40 & .37 \\
\hline \multirow[t]{2}{*}{$r$} & .96 & .99 & .98 & .98 \\
\hline & \multicolumn{4}{|c|}{$\mathrm{ISF}=16 \mathrm{~cd} / \mathrm{m}^{2}$} \\
\hline $\mathrm{b}$ & -1.88 & -1.47 & 1.23 & 1.76 \\
\hline $\mathrm{m}$ & 2.39 & 2.39 & .46 & .38 \\
\hline \multirow[t]{2}{*}{$r$} & .90 & .97 & .98 & .96 \\
\hline & \multicolumn{4}{|c|}{$I S F=32 \mathrm{~cd} / \mathrm{m}^{2}$} \\
\hline $\mathbf{b}$ & -1.06 & -.49 & 1.50 & 2.09 \\
\hline $\mathrm{m}$ & 2.19 & 2.11 & .41 & .33 \\
\hline$r$ & .93 & .93 & .97 & .95 \\
\hline
\end{tabular}

Note-ISF $=$ interstimulus field. $\quad * y=b+m \ln x . \quad * * y=b x^{m}$.

there are monotonic relations between stimulus duration and the estimated subjective contrast. It is also evident that there is no saturation below $85 \mathrm{msec}$. There were no differences among the scale values that appeared at different luminance levels. The best fitted logarithmic and power functions are shown in Table 1.

While both functions are appropriate for describing these results, with reference to the main purpose of this experiment, it is more important to note that under these conditions, the saturation level of the subjective experience of spatial contrast as a function of stimulus duration falls in the $100-\mathrm{msec}$ range. ${ }^{2}$

\section{EXPERIMENT 2}

\section{Effect of Stimulus Duration on Simple Reaction Time}

No a priori hypothesis can be made about the range of the critical stimulus duration using patternappearance stimulation and RT measure. However, studies employing homogeneous flash stimulation indicated much shorter critical duration than those obtained in Experiment 1 (Bernstein, Futch, \& Schurman, 1973; Kietzman \& Gillam, 1972; Mansfield, 1973).

\section{Method}

Subjects. The subjects were seven students and staff members, four males and three females, 19-31 years old.

Apparatus and Procedure. The same apparatus was used as in Experiment 1. Luminance was set at $20 \mathrm{~cd} / \mathrm{m}^{2}$, and the subjects were asked to fixate on a centrally located fixation cross. A trial consisted of a warning click followed by the stimulus pattern. The warning period was $1,100,1,200,1,300$, or $1,400 \mathrm{msec}$, and these periods appeared in random order. Sessions were preceded by a $5-$ min adaptation period. The task was to press a microswitch "as fast as possible" when the pattern appeared. A Devices 3251 counter was used for measuring reaction time to 
the nearest millisecond). Six stimulus durations $-5,10,15,20$, 40 , and $80 \mathrm{msec}-$ were used. A session consisted of 12 runs; that is, there were two runs with each duration, a run consisting of 40 stimuli. The first six responses were omitted, so the mean values of reaction times were calculated from 36 measures. The serial positions of runs with different stimulus durations were counterbalanced among subjects.

\section{Results and Discussion}

Mean reaction times for the two runs with the same stimulus duration were averaged across the seven subjects. Results are shown in Table 2 . There seems to be a marked decrease of RT up to $15-20 \mathrm{msec}$, while above this value no further change can be seen. A one-way analysis of variance was calculated, using $\mathrm{L}-\mathrm{L}_{0}$ data, where $\mathrm{L}_{0}$ is the lowest average RT for a given subject. The effect of stimulus duration appeared to be significant $[F(5,35)=3.56, p<.05]$. According to the orthogonal comparisons, RT decreased between 5 and $15 \mathrm{msec}$, while between 40 and $80 \mathrm{msec}$ it increased. The more conservative Newman-Keuls analysis evidenced significant effects only between the 5-msec stimulus and the other durations (except $10 \mathrm{msec}$ ).

These results are in sharp contrast with those obtained in Experiment 1, because the saturation level of the reaction time appeared to be less than $40 \mathrm{msec}$. There is a reaction time increase for the 80 -msec stimulation in comparison with the 40 -msec stimulus duration. This effect is comparable to the reaction time increase obtained by Raab, Fehrer, and Hershenson (1961) and Bernstein et al. (1973). In light of the divergence between the saturation level of contrast experience and reaction time, however, it seems to be doubtful to relate this reaction time increase to the Broca-Sulzer effect.

\section{EXPERIMENT 3}

\section{Effect of Stimulus Duration on Pattern-Specific Visual Evoked Potentials}

In this experiment, we attempted to replicate the results reported by Jeffreys and Axford (1972b, p. 35); that is, VEPs were recorded using different stimulus durations.

Table 2

Mean Reaction Time as a Function of Stimulus Duration

\begin{tabular}{ccc}
\hline & \multicolumn{2}{c}{ Reaction Time } \\
\cline { 2 - 3 } Stimulus & Mean & SD \\
\hline 5 & 212.7 & 25.83 \\
10 & 208.3 & 22.97 \\
15 & 204.5 & 22.21 \\
20 & 203.2 & 21.93 \\
40 & 203.0 & 19.32 \\
80 & 204.1 & 25.97 \\
\hline
\end{tabular}

Note-Stimulus duration and reaction time are in milliseconds.

\section{Method}

Subjects. The subjects were eight students and staff members, four males and four females, 19-31 years old.

Apparatus and Procedure. Visual stimulation was identical to that of the previous experiment. Luminance was $20 \mathrm{~cd} / \mathrm{m}^{2}$. Stimulus durations were $5,10,15,20,40$, and $80 \mathrm{msec}$. Stimuli of a given duration were given in blocks, one block consisting of $\mathbf{4 0}$ stimuli. The serial positions of the two blocks of each duration were counterbalanced among subjects. The interstimulus interval was set at $1,500 \mathrm{msec}$, and the subjects were asked to fixate on a centrally located cross. Sessions were preceded by a 5 -min adaptation period.

Visual evoked potentials were recorded from the midline, $5 \mathrm{~cm}$ above the inion. ${ }^{3}$ The connected earlobes served as common reference. Vertical eye movements were recorded using the EOG method, and electric activity was amplified by an EMG 4556 electroencephalograph (3.3-70 $\mathrm{Hz}, 3 \mathrm{~dB}$ points). Off-line averages were obtained from a Philips Analog 7 recorder by using an NTA $512 / \mathrm{b}$ averager. The first five responses were omitted from each run, and 30 responses were averaged.

\section{Results and Discussion}

Two subjects' responses are shown in Figure 2. The three pattern-specific components (CI, CII, and CIII), described by Jeffreys and Axford (1972a, $1972 b)$, are easily identifiable in all VEPs.

The mean latency values at different stimulus durations are shown in Table 3. As a function of stimulus duration, no significant latency change could be obtained. In Figure 3, average CI-CII and CII-CIII peak-to-peak values (averages of the means of the eight subjects) are shown, together with reciprocal values of the RTs obtained in Experiment 2. The analyses of variance indicated a significant duration effect on both VEP amplitude measures $[F(5,30)=$ $4.72, \mathrm{p}<.01$, for $\mathrm{CI}-\mathrm{CII}^{4}$ and $\mathrm{F}(5,35)=3.46, \mathrm{p}<.05$, for CII-CIII].

Using Newman-Keuls comparisons, the following significant differences appeared: For the CI-CII measures, $S \mathrm{msec}$ vs. $15,20,40$, and $80 \mathrm{msec}$, and 10 msec vs. $40 \mathrm{msec}(\mathrm{p}<.01)$; while for the CII-CIII measures, $5 \mathrm{msec}$ vs. $40 \mathrm{msec}(\mathrm{p}<.01)$, and $5 \mathrm{msec}$ vs. 20 and $80 \mathrm{msec}(\mathrm{p}<.05)$.

These results indicate a clear saturation effect between 10 and $40 \mathrm{msec}$. They are similar to those obtained by Jeffreys and Axford (1972b) and Spekreijse et al. (1973). A striking feature of all three experiments is the lack of any latency change, while the spatial contrast as an independent variable has a clear effect on pattern-specific VEP latencies (Czigler, 1978; MacKay \& Jeffreys, 1973). So, in spite of the similar perceptual experience, there are certain divergences concerning the effect of the two variables on VEP.

\section{EXPERIMENT 4}

\section{Effect of Stimulus Duration on Visual Evoked Potential and Reaction Time}

In Experiment 2, reaction time for the 40-msec stimulus appeared to be shorter than the reaction time for the 5-msec stimulation, and VEP amplitude 

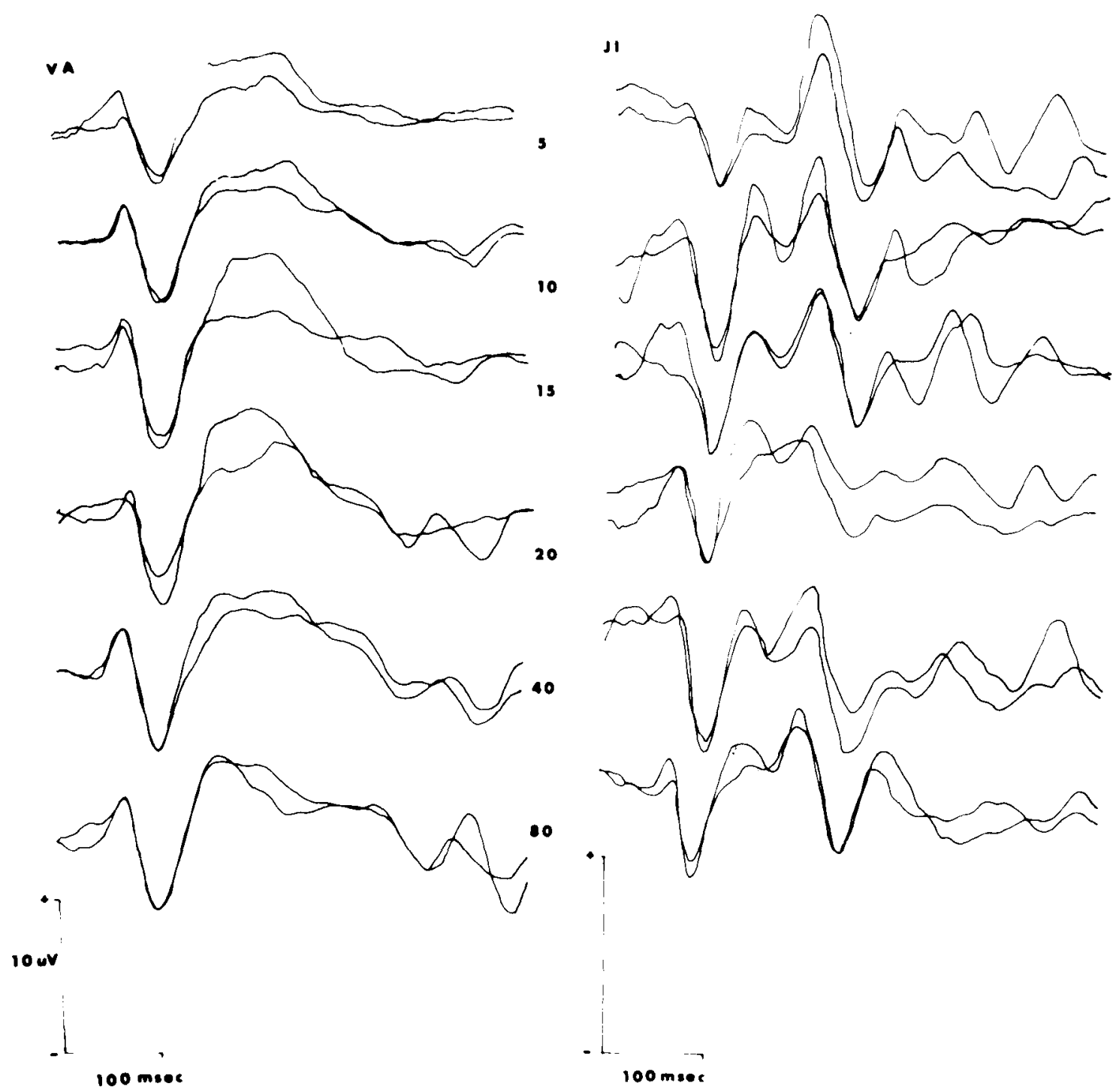

Figure 2. Two subjects' occipital evoked potentials as a function of stimulus duration (Experiment 3). Digits indicate the stimulus duration.

in Experiment 3 appeared to be larger for the 40 msec duration than for the 5-msec duration. VEP and RT data, however, were obtained under slightly different conditions. The purpose of this experiment was to test the reliability of this relationship when VEP and RT are measured simultaneously.

Table 3

Mean Latencies of Occipital Components in Experiment 3

\begin{tabular}{|c|c|c|c|c|c|c|}
\hline \multirow[b]{3}{*}{$\mathrm{D}$} & \multicolumn{6}{|c|}{ Latencies of the Components } \\
\hline & \multicolumn{2}{|c|}{$\mathrm{CI}$} & \multicolumn{2}{|c|}{$\mathrm{CII}$} & \multicolumn{2}{|c|}{ CIII } \\
\hline & Mean & SD & Mean & $\mathrm{SD}$ & Mean & SD \\
\hline 5 & 79 & 15.8 & 111 & 12.4 & 166 & 26.8 \\
\hline 10 & 80 & 12.3 & 111 & 14.5 & 169 & 24.0 \\
\hline 15 & 80 & 10.3 & 110 & 12.6 & 165 & 23.6 \\
\hline 20 & 79 & 9.6 & 111 & 10.8 & 165 & 21.9 \\
\hline 40 & 81 & 11.4 & 109 & 10.1 & 167 & 28.6 \\
\hline 80 & 80 & 12.1 & 110 & 9.9 & 162 & 23.8 \\
\hline
\end{tabular}

Note-D - stimulus duration. Stimulus duration and latencies are in milliseconds.

\section{Method}

Subjects. The subjects were five staff members, three males and two females, 24-31 years old.

Apparatus and Procedure. Stimulus and reaction time measurement were identical to the procedure of Experiment 2, while VEP measurement was identical to the procedure of Experiment 3. Stimulus durations were 5 and $40 \mathrm{msec}$. Besides the lower half-field stimulation, there were runs with stimulation of the left half-field.

\section{Results and Discussion}

Two subjects' responses are shown in Figure 4. Visual evoked potentials to lower half-field stimulation are similar to those obtained in Experiment 3. Left half-field stimulation evoked many fewer characteristic responses. Since midline electrodes were used, the small CI component can be attributed to the scalp distribution of this component (Jeffreys \& Axford, 1972a), and the cancellation of responses originated from the representation of the upper and lower quadrant in the case of the CII component (Jeffreys \& Axford, 1972b). Because of the absence 




Figure 3. Average CI-CII (๑- - $\bullet)$ and CII-CIII (口- - - ) peak-to-peak amplitudes (Experiment 3) and reciprocal values of simple reaction times $(\Delta---\Delta)$ (Experiment 2 ) as a function of stimulus duration.
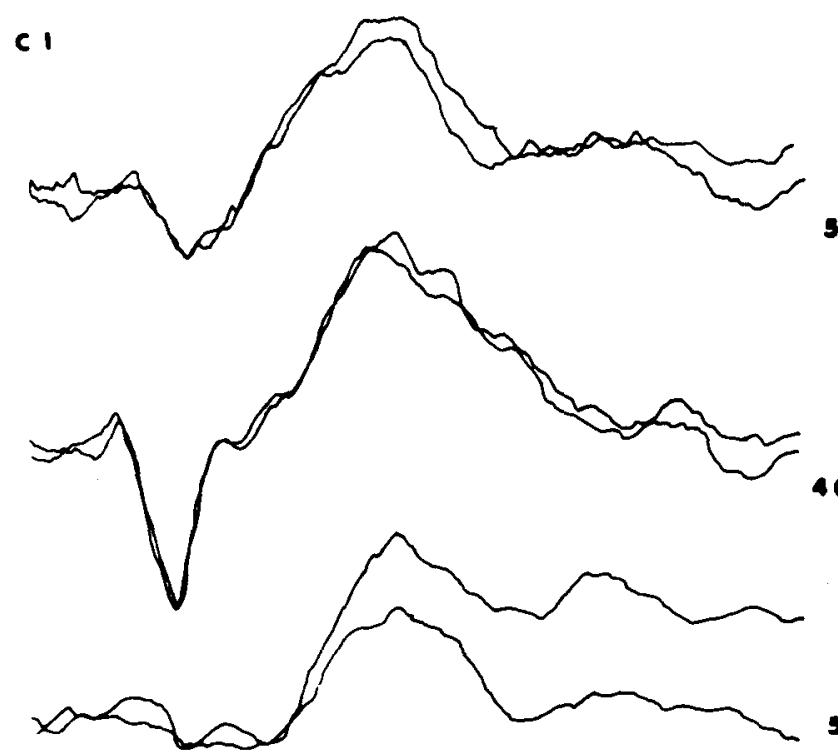

$\mathbf{s}$
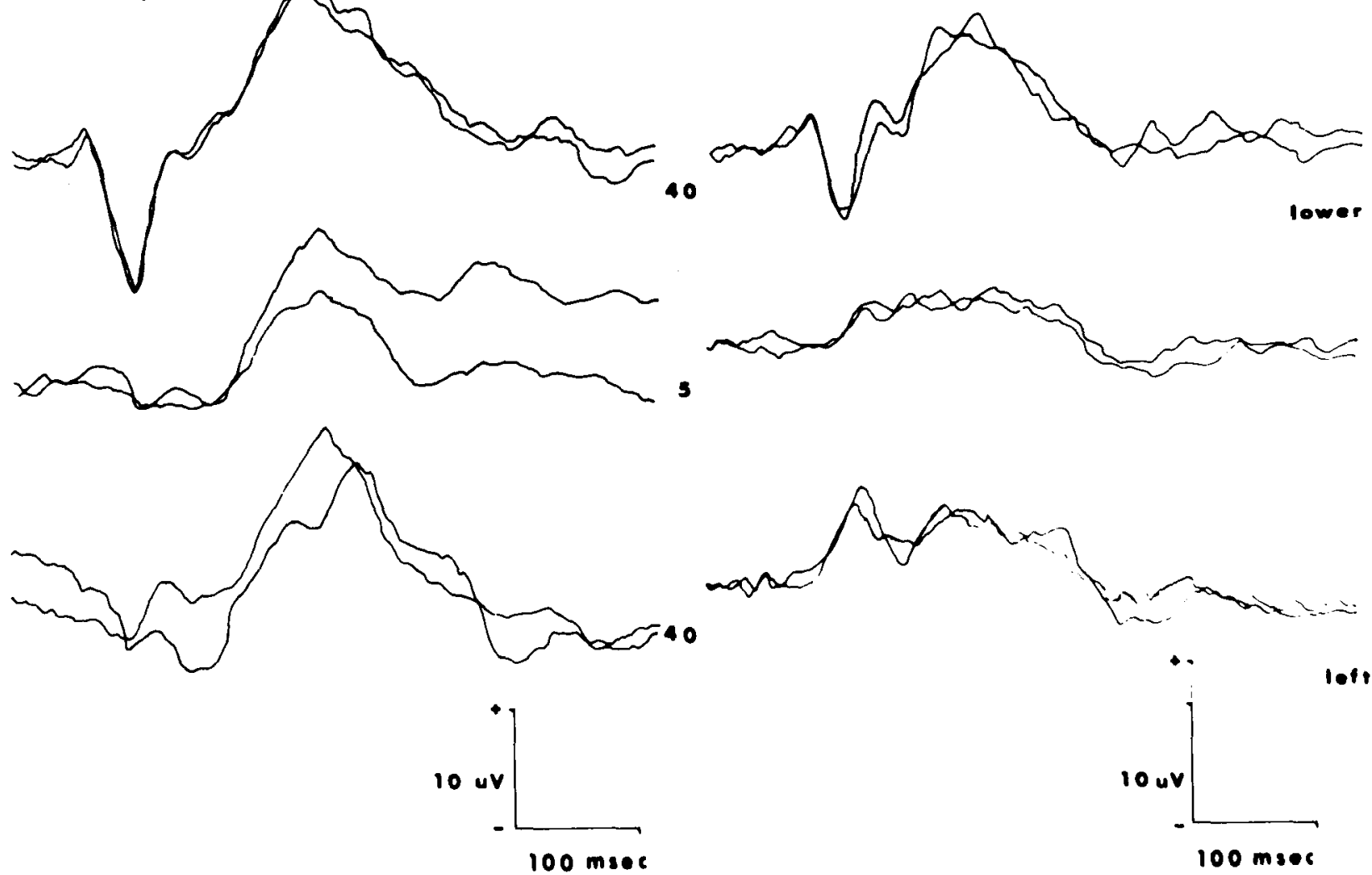

of reliable components, VEP measurements were restricted to the lower half-field responses. As in Experiment 3, no latency changes were obtained. CICII and CII-CIII peak-to-peak data are shown in Table 4. In both cases, the responses evoked by the 40 -msec stimulation are larger $[\mathrm{t}(4)=2.9, \mathrm{p}<.05$ and $t(4)=3.6, p<.05$ for CI-CII and CII-CIII, respectively]. Reaction time data are shown in Table 5. An analysis of variance indicated a significant treatment effect $[F(3,12)=4.44, p<.05]$ with a significant duration effect $(p<.05)$. No other effect appeared to be significant.

\section{CONCLUSIONS}

The main conclusion of this study is the clear divergence of the perceptual experience on one side and the reaction time and visual evoked potential on the other side, in regard to pattern stimulus duration. This divergence is evidenced by the different saturation level of the spatial contrast experience in comparison with the other two measures as a function of stimulus duration; that is, the former is above $85 \mathrm{msec}$, while the latter two are below $40 \mathrm{msec}$. It could be

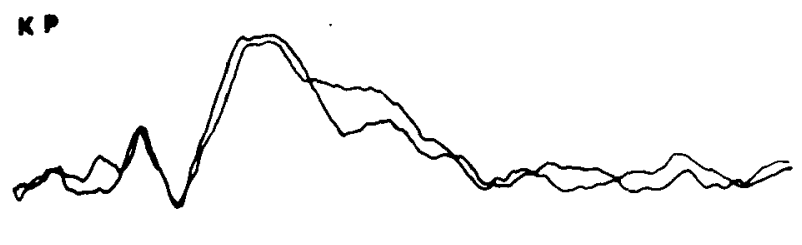

Figure 4. Two subjects' occipital evoked potentials as a function of stimulus duration (indicated by digits) and of the stimulated half of the visual field (lower or left) (Experiment 4). 
Table 4

Mean Amplitude Values (CI-CII and CII-CIII) of Visual Evoked Potentials in Experiment 4

\begin{tabular}{rccccc} 
& \multicolumn{4}{c}{ Amplitude (in Microvolts) } \\
\cline { 2 - 3 } $\begin{array}{c}\text { Milli- } \\
\text { seconds }\end{array}$ & Mean & SD & & Mean & CII-CIII \\
\hline 5 & 4.8 & 1.3 & 13.0 & 3.9 \\
40 & 8.8 & 3.0 & 17.8 & 6.7 \\
\hline
\end{tabular}

Note-Occipital responses are to lower half-field stimulation.

Table 5

Mean Values of Simple Reaction Times to Different Stimulus Durations in Experiment 4

\begin{tabular}{|c|c|c|c|c|}
\hline \multirow{3}{*}{$\begin{array}{l}\text { Stimulus } \\
\text { Duration }\end{array}$} & \multicolumn{4}{|c|}{ Reaction Time } \\
\hline & \multicolumn{2}{|c|}{$\begin{array}{c}\text { Lower Half-Field } \\
\text { Stimulation }\end{array}$} & \multicolumn{2}{|c|}{$\begin{array}{l}\text { Left Half-Field } \\
\text { Stimulation }\end{array}$} \\
\hline & Mean & SD & Mean & SD \\
\hline 5 & 205.4 & 10 & 215.3 & 17 \\
\hline 40 & 196.5 & 14 & 203.3 & 21 \\
\hline
\end{tabular}

Note-Reaction time and stimulus duration are given in milliseconds.

argued that the task demands of the scaling procedure on the one hand and the SRT task and pure fixation on the other hand were different. This difference would affect the VEPs in such a way as to reduce the saturation level in tasks with less emphasis on the magnitude of contrast. In fact, task involvement in selection attention tasks can modify the VEP (Buchsbaum \& Drago, 1979; Eason, Harter, \& White, 1969; Van Voorhis \& Hillyard, 1977). It seems, however, that in order to obtain attention effects on the specific VEP components, the task must be difficult and a short interstimulus interval is needed (Van Voorhis \& Hillyard, 1977). In our scaling procedure, the subjects were free to assign any value to the stimuli, and the intertrial interval was much longer than the interval used in selective attention experiments. Thus, the task demand account in the present study seems to be improbable.

The pattern of results of our experiments has some implications about the role of the processes underlying the components of pattern-specific evoked potentials in the flow of human information processing. A process of lower saturation cannot be considered as a correlate of mechanisms underlying a process of higher saturation level. So, it is supposed that processes underlying evoked potentials specific to pattern stimulation have no direct causal relationship to the measured magnitude of contrast experience. Reaction time in a "stimulus set" (Broadbent, 1970) situation, however, can be triggered by a more or less automatic way of information processing. Patternspecific components of visual evoked potentials can be related to such activity of the visual system.

\section{REFERENCES}

Bernstein, I. H., Futch, D. G., \& Schurman, D. L. Some exposure duration effects on simple reaction time. Journal of Experimental Psychology, 1973, 97, 317-322.

Broadeent, D. E. Stimulus set and response set: Two kinds of selective attention. In D. I. Mostofsky (Ed.), Attention: Contemporary theory and analysis. New York: AppletonCentury-Crofts, 1970.

Buchsbaum, M. S., \& Drago, D. Hemispheric asymmetry in the effects of attention on the visual evoked response. In J. E. Desment (Ed.), Language and hemispheric specialization in man: Event-related cerebral potentials. Progress in clinical neurophysiology (Vol. 3). Basel: Karger, 1979.

Camprell, F. W., \& Kulikowski, J. J. The visual evoked potential as a function of contrast of a grating pattern. Journal of Physiology, 1972, 222, 345-356.

Cam pbei.l, F. W., \& MAFFei, L. Electrophysiological evidence for the existence of orientation and size detectors in human visual system. Journal of Physiology, 1970, 207, 635-652.

CATtELL, J. McK. The influence of the intensity of the stimulus on the length of the reaction time. Brain, 1886, 9, 512-515.

CzIGiLER, I. Effects of spatial contrast on simple reaction time and visual evoked potentials. In L. Kardos (Ed.), Problems of information processing and perceptual organization. Budapest: Akadémiai Kiadó, 1978.

Eason, R. G., Harter, M. R., \& White, C. T. Effects of attention and arousal on visual evoked cortical potentials and reaction time in man. Physiology \& Behavior, 1969, 4, 283-289.

Fiorintini, A., \& MaffFi, L. Contrast perception and electrophysiological correlates. Journal of Physiology, 1973, 231, 61-69.

Harter, M. R., \& White, C. T. Evoked cortical responses to checkerboard patterns: Effect of check-size as a function of visual acuity. Electroencephalography and Clinical Neurophysiology, 1970, 28, 48-53.

JFFFriys, D. A., \& AxForD, J. G. Source locations of patternspecific components of human visual evoked potentials. I. Component of striate cortical origin. Experimental Brain Research, 1972, 16, 1-21. (a)

Jefrreys, D. A., \& AXFond, J. G. Source locations of patternspecific components of human visual evoked potentials. II. Component of extrastriate cortical origin. Experimental Brain Research, 1972, 16, 22-40. (b)

Kietzman, M. L., \& Gillam, B. J. Visual temporal integration and simple reaction time. Perception \& Psychophysics, 1972, $11,333-340$.

MACKAY, D. M. Psychophysics of perceived intensity: A theoretical basis for Fechner's and Stevens' laws. Science, 1963, 139, 1213-1216.

M ACKAY, D. M., \& JeFFreys, A. D. Visually evoked potentials and visual perception in man. In R. Jung (Ed.), Handbook of sensory physiology (Vol. 7/3). Berlin: Springer-Verlag, 1973.

Mansfiel.D, R. J. W. Latency functions in human vision. Vision Research, 1973, 13, 2219-2234.

Marg, E., Frff.man, D. N., Peltzman, P., \& Goldstein, P. J. Visual acuity development in human infants: Evoked potential measurements. Investigative Ophthalmology, 1976, 15, 150-153.

RaAa, D. H., Feitrer. E., \& Hershenson, M. Visual reaction time and the Broca-Sulzer phenomenon. Journal of Experimental Psychology, 1961, 61, 193-199.

REGiAN, D. Evoked potentials in psychology, sensory physiology and clinical medicine. London: Chapman \& Hall, 1972.

SoкоL, S. Measurement of infant visual acuity from pattern reversal evoked potentials. Vision Research, 1978, 18, 33-39.

Sperreisse, H., Van der Tweel, L. H., \& Zuidema, Th. Contrast evoked responses in man. Vision Research, 1973, 13, $1577-1601$.

Strvf Ns, S. S. Issues in psychophysical measurement. Psychological Review, 1971, 78, 426-450.

VAn Vorruts, S., \& Hhicyard, S. A. Visual evoked potentials 
and selective attention to points in space. Perception \& Psychophysics, 1972, 22, 54-62.

Vaughan, H. G., Jr., Costa, L. D., \& Gilden, L. The functional relation of visual evoked response and reaction time to stimulus intensity. Vision Research, 1966, 6, 645-656.

Vaughan, H. G., JR., \& Hull, R. C. Functional relationship between stimulus intensity and photically evoked cerebral responses in man. Nature, 1965, 266, 720-722.

\section{NOTES}

1. In the present paper, we refrain from discussing the logarithmic vs. power function controversy. On this issue, the authors agree with the opinions expressed by MacKay (1963) and Regan (1972, pp. 31-34).
2. Similar values were obtained in unpublished experiments using signal detection measures. The task was to detect contrast differences using stimuli of different duration. The $d$ ' value decreased dramatically when a stimulus of $120 \mathrm{msec}$ duration was used in comparison with that obtained using an 80 -msec stimulus. 3. Vertex responses were also measured, but no responses significant from the point of view of the present problems appeared, so we refrain from the presentation of those results.

4. There was no $\mathrm{Cl}$ for one subject.

(Received for publication April 15, 1980; revision accepted June 3,1980 .) 